\title{
Screening of Anxiety and Depression in Patients With Fibromyalgia From 18 to 65 Years Old and Its Relationship With the Severity of Fibromyalgia and Quality of Life
}

\author{
Christian Paternina Gonzalez ${ }^{1}$, Elias Forero Illera ${ }^{2}$, Carmen Laborde Cárdenas ${ }^{3}$, Eduardo Navarro Jimenez ${ }^{3}$, Pedro \\ Gomez Mendez ${ }^{1}$, Vanessa Valenzuela Peralta ${ }^{4} \&$ Luis Carlos Luque Narvaez \\ ${ }^{1}$ Especialidación en psiquiatría, Departamento de medicina, Universidad del Norte, Barranquilla, Colombia \\ ${ }^{2}$ Especialización en medicina interna, Departamento de medicina, Universidad del Norte, Barranquilla, Colombia \\ ${ }^{3}$ Facultad de ciencias de la salud, programa de medicina, Universidad Simón Bolívar, Barranquilla, Colombia \\ ${ }^{4}$ Facultad de medicina, Universidad de Cartagena, Cartagena, Colombia \\ ${ }^{5}$ Departamento de Gestión Organizacional, Universidad de la Costa CUC, Barranquilla, Colombia \\ Correspondence: Eduardo Navarro-Jiménez, Universidad Simón Bolívar, Barranquilla, Colombia. Orcid: \\ http://orcid.org/0000-0002-8171-662X. E-mail: edunavjim@gmail.com
}

Received: September 7, 2018 Accepted: October 22, 2018 Online Published: November 5, 2018

doi:10.5539/gjhs.v10n12p12 URL: https://doi.org/10.5539/gjhs.v10n12p12

\begin{abstract}
Objective: To identify the relationship between anxiety and depression with the severity of fibromyalgia and quality of life in patients aged 18 to 65 years, clinic of rheumatology of Barranquilla.

Methods: Observational, descriptive, comparative cross-sectional study. Patients with fibromyalgia who attend the external consultation of rheumatology will be surveyed. The questionnaires to be applied are the Fibromyalgia Impact Questionnaire Revised (Spanish version), Health Questionnaire SF-36, Patient Health Questionnaire and a Scale of 7 questions for generalized anxiety disorder. The data collected in this descriptive study will be analyzed by means of frequency and association measures. The analysis of association between sociodemographic factors and clinical characteristics will be carried out with bivariate analysis and the comparison of qualitative or categorical variables will be done through the analysis of variance, to compare variables of ordinal type and variables of type ratio.
\end{abstract}

Results: $34.2 \%$ of the patients did not present anxiety whereas $83.6 \%$ of the patients had some degree of depression. $50 \%$ of the patients had moderate, severe and extreme degrees of depression. An association was found between severity of fibromyalgia with anxiety, depression and quality of life $(\mathrm{p}<0.05)$.

Conclusion: A directly proportional relationship was found between the severity of depression and anxiety and the severity of FM. An elevated score in the FIQR, lower weighted scores for quality of life in the participants, in addition to greater severity in the scales GAD - 7 and PHQ - 9, all score to lower quality of life.

Keywords: fibromyalgia, depression, anxiety, quality of life, rheumatology

\section{Introduction}

Fibromyalgia is a medical condition, neither progressive nor degenerative, whose prevalence varies from $2 \%$ to $4 \%$ in the general population. Within the symptomatic spectrum of this entity are widespread chronic pain, fatigue, mood disorders, sleep disturbances and deterioration of quality of life (Kaltsas \& Tsiveriotis, 2013; Talotta et al., 2017). Pain is the predominant symptom, being accompanied more frequently by cognitive deterioration and sleep disorders. Alodinia and hyper- algesia can also be found (Kaltsas \& Tsiveriotis, 2013). Likewise, comorbidity with psychiatric disorders are frequent, with depression and anxiety being the most common. The frequency for depressive disorder ranges between $20 \%$ and $80 \%$, while for anxiety disorder ranges from $13 \%$ to $63.8 \%$ (de Vida \& Fibromialgia, 2010; Fietta \& Manganelli, 2007).

Currently, the etiology of FM remains undetermined and unclear. It is known to be due in part to increased sensory and pain processing, although the exact mechanisms are unknown (Chinn, Caldwell, \& Gritsenko, 2016). Being constituted as a multifactorial entity, its pathophysiology remains a conjunction of a series of factors such as 
anomalies in the autonomic and neroendocrine nervous system, genetic factors, some types of infections (Lyme disease, HIV and hepatitis C), psychosocial factors, physical traumas, and psychological stress (Buskila, Atzeni, \& Sarzi-Puttini, 2008; Chavez Hidalgo, 2013; Clauw, 2014).

In the affected population there is no pathological evidence, obvious deformity or laboratory test to justify the symptoms, and as such they remain questionable. Those affected by FM usually mention that the spouse, health professional, colleagues and/or society do not "understand" them (Cunningham \& Jillings, 2006; Kool, van Middendorp, Boeije, \& Geenen, 2009). The constant psychic-physical suffering of patients with FM negatively affects their quality of life, functioning and mood, as they must face an "invisible disability" every day (Fietta \& Manganelli, 2007).

In Colombia specifically, studies on the prevalence of fibromyalgia have not been found but it is believed to affect $1-3 \%$ of the general population (Fernández Ávila, 2016).

\section{Materials and Methods}

Observational, descriptive, comparative cross-sectional study. The sample consisted of 38 people with a diagnosis of fibromyalgia who attended the outpatient clinic of a rheumatology clinic, from 18 to 65 years old, of both sexes. Clinical information was obtained through previously validated surveys: Fibromyalgia Impact Questionnaire Revised (FIQR), Spanish version, SF-36 Health Questionnaire, Patient Health Questionnaire (PHQ - 9), 7 question scale for generalized anxiety disorder (GAD-7 for its acronym in English). The information was collected between the months of August and October 2017.

The data collected in this descriptive study were analyzed by means of frequency and association measures. Regarding the frequency measurements for the qualitative variables, they were expressed through ratios, proportions, percentages and rates; the quantitative variables were analyzed through measures of central tendency (averages) and dispersion measures (standard deviations).

The analysis of the association between the sociodemographic factors and the clinical characteristics were performed with bivariate analysis and the comparison of the qualitative or categorical variables was done by means of the analysis of variance, to compare variables of ordinal type and quantitative type variables of ratio. The Kolmogorov-Smirnov test was performed to verify the normal distribution of the data.

This research is a research with minimal risk, in accordance with Colombian regulations on health research (Ministerio de Salud y Protección Social de Colombia, 1993). The patients signed an informed consent. This research was approved by the Health Research Ethics Committee of the Universidad del Norte de Barranquilla.

\section{Results}

Women represented $94.7 \%$ of the patients and men $5.3 \%$. The highest percentages of participants $(>20 \%)$ were between the ages of 49 to 58 years and 39 to 48 years of age respectively. The lowest percentages $(<20 \%)$ were in the ranges of 19 to 28 years, from 29 to 38 years and from 59 to 68 years. The most frequent marital status among the respondents was married $(52.6 \%)$, followed by divorced $(21.1 \%),(15.8 \%)$ in a relationship but not married, single and widowed (2.6\%). $63.2 \%$ of patients said they work and $36.8 \%$ said they do not.

$34.2 \%$ of the patients did not present anxiety, $31.6 \%$ with moderate anxiety, $21.1 \%$ with severe anxiety and $13.2 \%$ mild anxiety (see Table 1).

Table 1. Severity of anxiety according to GAD 7

\begin{tabular}{lll}
\hline & Frequency & Percentage \\
\hline No anxiety & 13 & 34,2 \\
Mild anxiety & 5 & 13,2 \\
Moderate anxiety & 12 & 31,6 \\
Severe anxiety & 8 & 21,1 \\
Total & $\mathbf{3 8}$ & $\mathbf{1 0 0 , 0}$ \\
\hline
\end{tabular}

$83.6 \%$ of the patients had some degree of depression. Of these, mild depression followed by moderate depression was more frequent. Severe depression constituted $10.5 \%$ of the cases (Table 2). 
Table 2. Severity of depression according to PHQ-9

\begin{tabular}{lll}
\hline & Frequency & Percentage \\
\hline No depression & 10 & 26,3 \\
Mild depression & 14 & 36,8 \\
Moderate depression & 7 & 18,4 \\
Moderately severe depression & 3 & 7,9 \\
Severe depression & 4 & 10,5 \\
Total & 38 & 100,0 \\
\hline
\end{tabular}

$50 \%$ of the patients experienced mild FM symptoms. The remaining 50\% had grades ranging between moderate, severe and extreme; presenting similar frequencies. (Table 3)

Table 3. Severity of fibromyalgia according to FIQR

\begin{tabular}{lll}
\hline & Frequency & Percentage \\
\hline Mild Fm & 19 & 50,0 \\
Moderate Fm & 8 & 21,1 \\
Severe Fm & 5 & 13,2 \\
Extreme Fm & 6 & 15,8 \\
Total & 38 & 100,0 \\
\hline
\end{tabular}

It is observed that the greater degree of severity of anxiety there is a greater degree of severity of fibromyalgia (Graph 1).

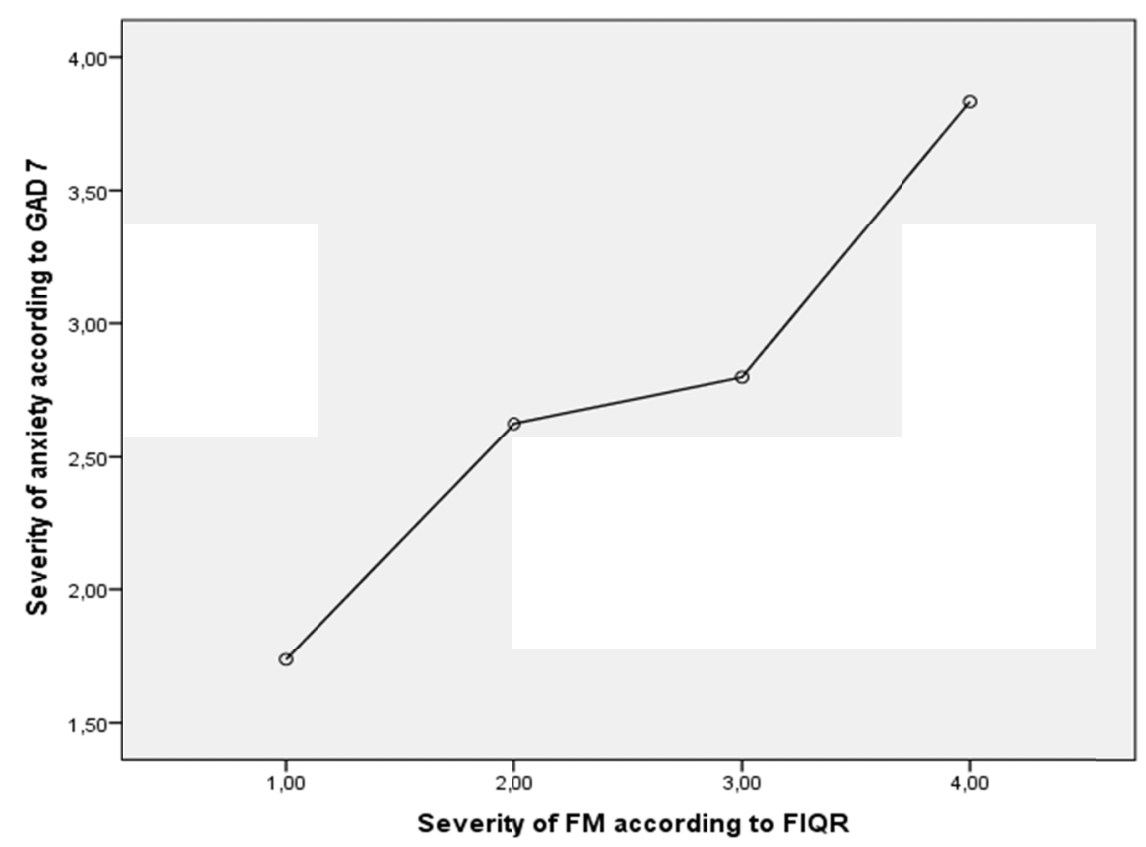

Graph 1. Severity of fibromyalgia and severity of anxiety (GAD-7)*

* At $\mathrm{x}$ axis; $1=$ Mild Fm, Moderate $\mathrm{Fm}=2$, Severe $\mathrm{Fm}=3$, Extreme $\mathrm{Fm}=4$

It is observed that the greater degree of severity of depression there is a greater degree of severity of fibromyalgia 
(Graph 2).

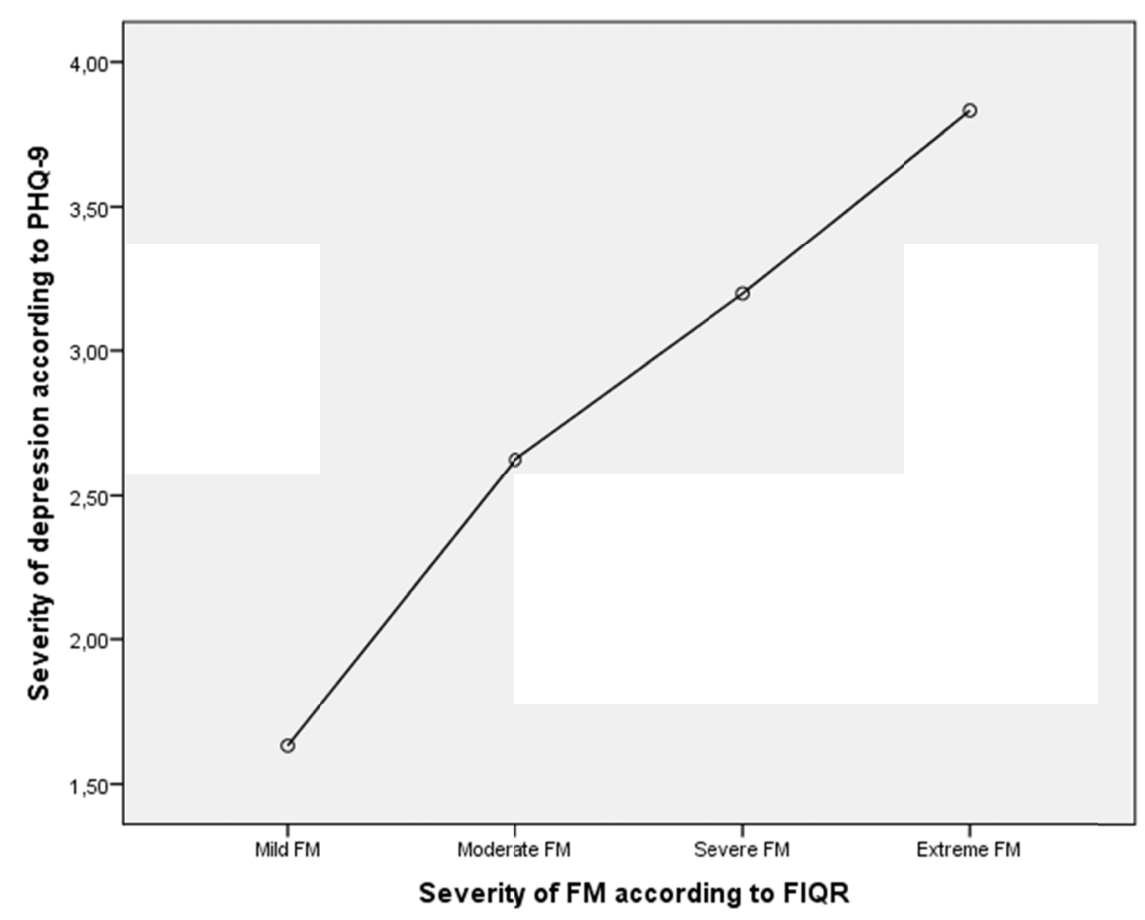

Graph 2. Severity of fibromyalgia and severity of depression (PHQ-9)

* At $\mathrm{x}$ axis; $1=$ Mild Fm, Moderate Fm=2, Severe Fm=3, Extreme Fm=4

It is observed that the greater the severity of fibromyalgia, the lower the quality of life (Graph 3).

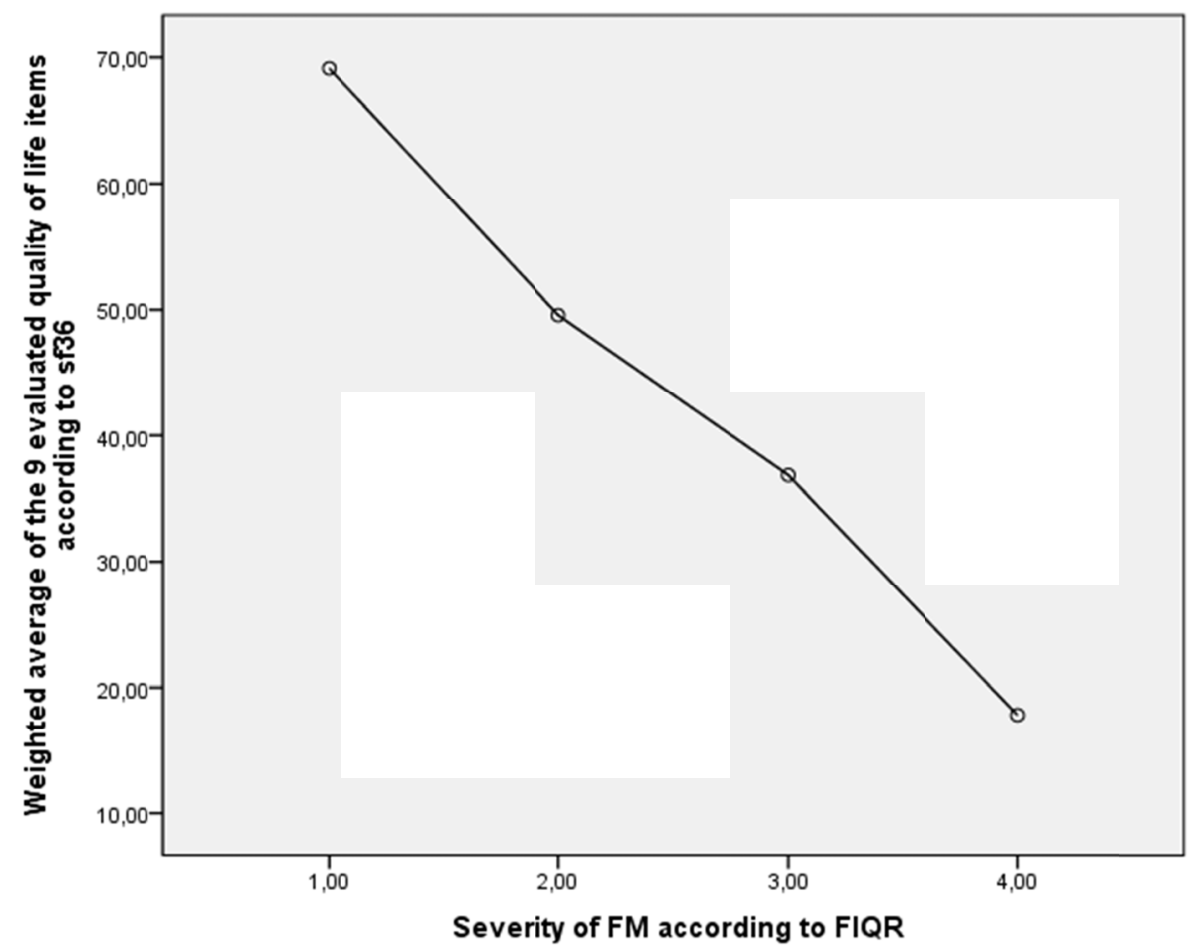

Graph 3. Fibromyalgia severity and weighted quality of life (SF-36)

* At $\mathrm{x}$ axis; $1=$ Mild Fm, Moderate $\mathrm{Fm}=2$, Severe $\mathrm{Fm}=3$, Extreme $\mathrm{Fm}=4$ 
It is observed that the lower the quality of life, the greater the severity of depression (Graph 4).

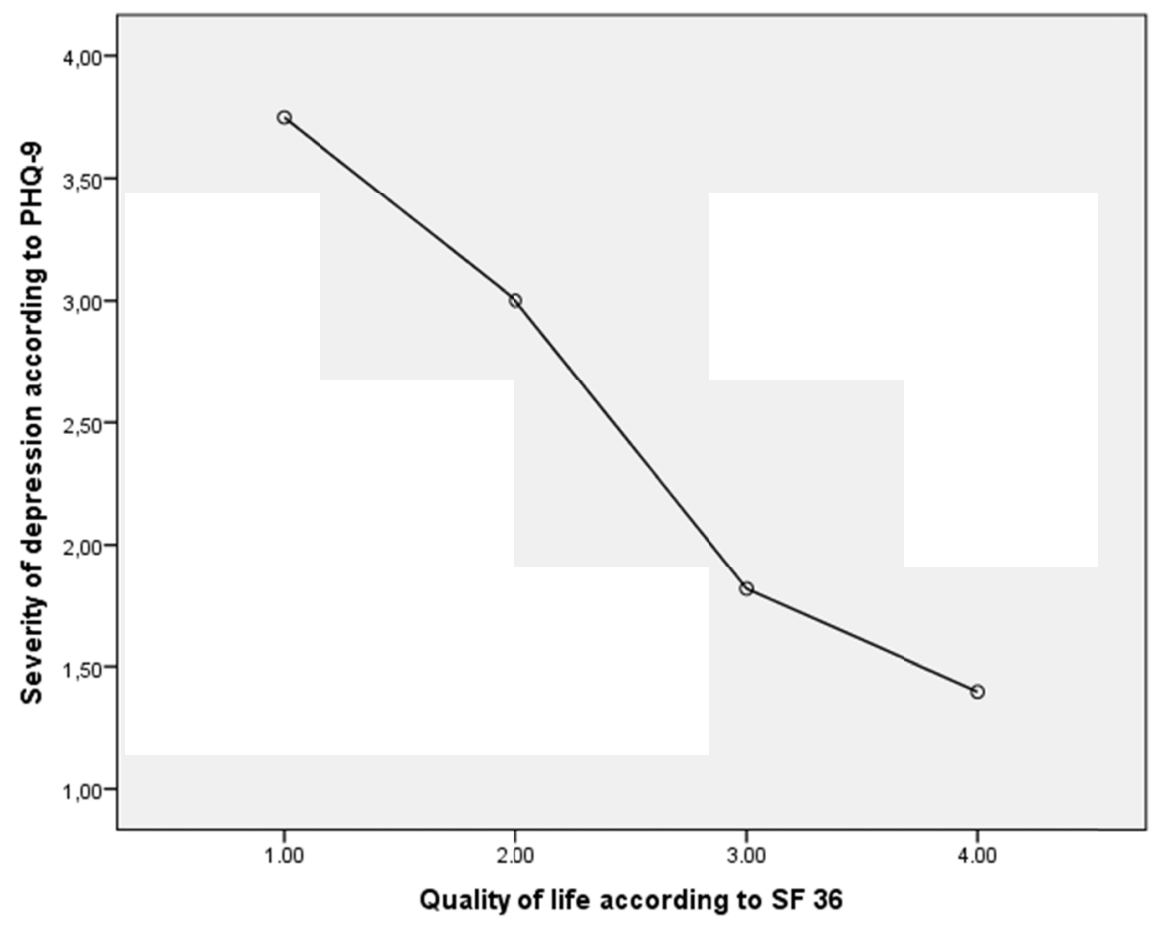

Graph 4. Severity of depression with quality of life (SF36)

* At $\mathrm{x}$ axis; $1=$ Mild Fm, Moderate Fm=2, Severe Fm=3, Extreme Fm=4

It is observed that the lower the quality of life, the greater the severity of anxiety (Graph 5).

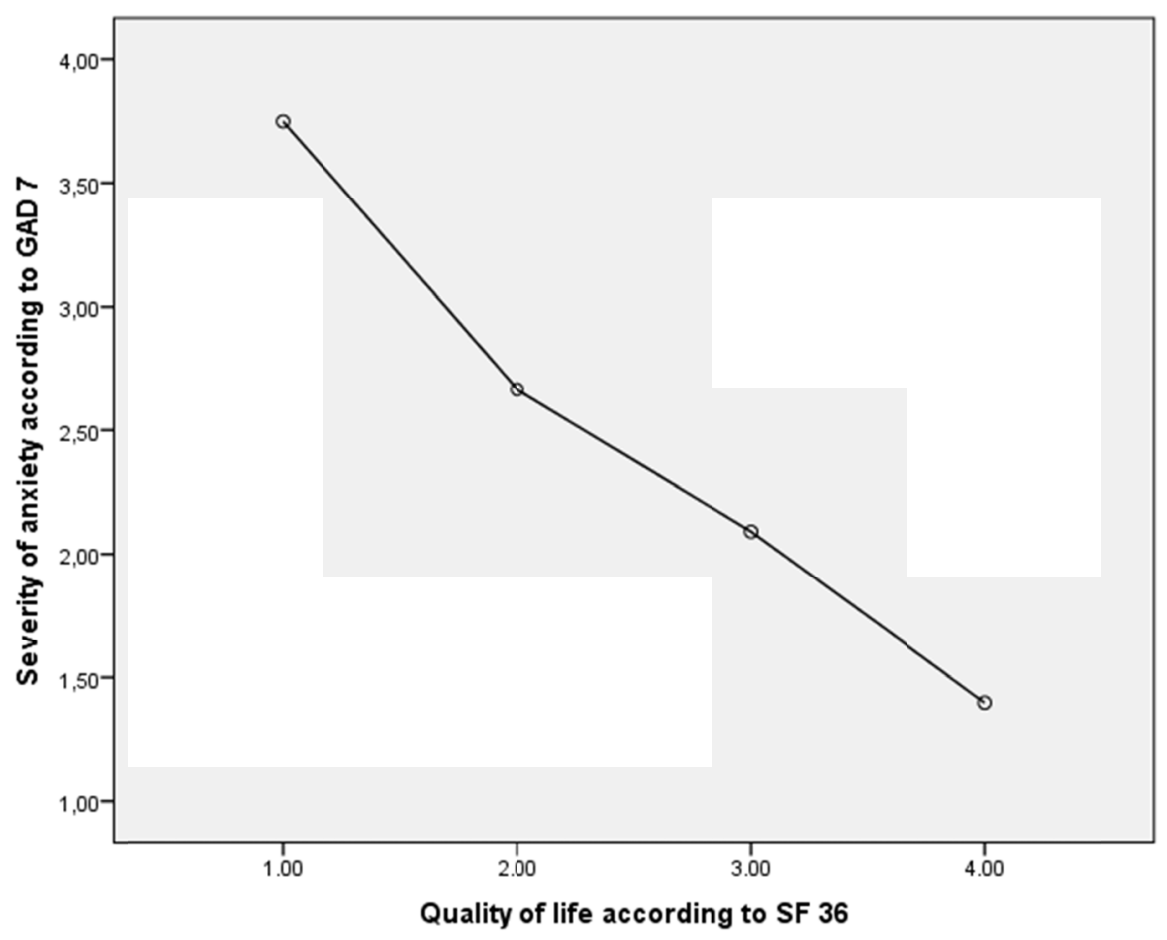

Graph 5. Severity of anxiety with quality of life (SF36)

* At $\mathrm{x}$ axis; $1=$ Mild Fm, Moderate Fm=2, Severe Fm=3, Extreme Fm=4 


\section{Discussion}

The majority of the participants in this study are female ( $94.7 \%$ of the total sample). Data that coincides with the literature that states that fibromyalgia is 7 to 10 times more frequent in women than in men (Lawrence et al., 2008).

Jiao et al. (2014) evaluated 978 patients with FM, locating the relationship between age with symptomatic severity and quality of life in this population group. Among their findings, they reported that young and middle - aged patients had worse scores in SF - 36 in addition to greater symptomatic severity. Among other things there was a tendency to find diminished scores in the SF - 36 with increased scores in the FIQR (Jiao, Vincent, Cha, Luedtke, \& Oh, 2014).

With respect to the age of patients with FM Moukaddem et al. (2017), they found that $58.8 \%$ of the sample (20 patients) were between 30 and 49 years old, while 29.4\% (10 patients) were $>50$ years (Moukaddem et al., 2017). The data of this study support the figures described in relation to the prevalence of FM in different age groups, the majority being between 49-58 years, followed by the group between 39-58 years (McNally, Matheson, \& Bakowsky, 2006; Moukaddem et al., 2015; Queiroz, 2013).

In this study it was found that $36.8 \%$ of the patients had a university degree, $21.1 \%$ had technical degrees, and $28.9 \%$ had a bachelor's degree, for a total of $86.8 \%$, while only $13.2 \%$ of the total of the sample had limited schooling; which coincides with results of other studies conducted by Bannwarth et al. (2009). In another study it was found in a cohort of French patients with FM, that low schooling was configured as a risk factor in that population (Bannwarth et al., 2009; Björkegren, Wallander, Johansson, \& Svärdsudd, 2009; Queiroz, 2013).

The socioeconomic level could be related to the average of income that patients have, being able to establish a causal relationship between lower socioeconomic status and lower income. In this study the people belonging to levels 1, 2 and 4, were presented in the same amount, while levels 5 and 6 were found in smaller proportion (it may prove beneficial rather that writing about levels to state it clearly as a debate- as evident in the next sentence). McNally et al. (22016, Establish that women with the worst economic income in their sample were more likely to suffer from FM, than those with higher income (McNally et al., 2006). The above is considered as a trend in most studies related to FM, the lower the income, the greater the probability of presenting the disease (Queiroz, 2013). Perrot et al. (2013), described that 55.9\% of patients with FM work (Bannwarth et al., 2009). Similar results were obtained in this study (could one sensitively think of reasons as to why?).

The comorbidity of psychiatric disorders with FM is clearly established theoretically and in various research studies Anxiety disorders, Major depressive disorder, post-traumatic stress disorder and stress have been widely related to the prevalence and severity of FM. Within this research, it was found that values that warrant a strict follow-up for GAD according to GAD-7 (> 10) that correspond to moderate anxiety in the future, are found in 31.6\% for moderate anxiety and $21.1 \%$ for severe anxiety, for a total of $52.7 \%$. It is important to add to the above that $65.9 \%$ of the total, present some degree of anxiety. The above reconfirms the data obtained in many other studies, which establish TAG as an active comorbidity in people with FM. The above agrees with the findings of authors such as Alok, Weir and Martínez (Alok, Das, Agarwal, Salwahan, \& Srivastava, 2010; Martinez, de Melo Casagrande, Ferreira, \& Rossatto, 2013; Weir et al., 2006).

A large number of studies supports the fact that people suffering from rheumatological diseases suffer from depression. Fietta et al., Mentioned that the prevalence of depression in patients with FM was between $20-80 \%$ (Fietta \& Manganelli, 2007). Alok et al., found that $88.3 \%$ of their sample had a diagnosis of depression (Alok et al., 2010). 83.3\% of the patients with FM gathered by Aguglia et al., Had depressive symptoms (Aguglia, Salvi, Maina, Rossetto, \& Aguglia, 2011). The information collected in reference to TDM and its comorbidity with FM, $83.6 \%$ of the participants in this study had some degree of depression.

Generally the results in the studies of patients with FM are interpreted by particular item of the scale. The majority of the participants in this study, when averaging all the results, obtained scores below 50, demonstrating that the perception of the quality of life of most of the participants was affected by the different symptoms of the disease.

Taking into account the impact of FM on health status and quality of life, the most compromised domains in the group of patients in this study were the transition in health, followed by pain and later the physical role. That is, the participants were of the opinion that their health is something worse now than a year ago, besides that they present intense pain and that their physical health generates some degree of difficulty in their work or other daily activities. The results with the highest score in the SF - 36 were emotional role, mental health and social health. This may be related to the fact that most patients were employed, not letting factors such as emotional problems affect their daily lives. It is also striking that despite the fact that most patients had some degree of depression or anxiety, mental health stood out among the highest components of the SF - 36 (Bannwarth et al., 2009; Buskila et al., 2008; 
Hernández-Petro \& Cardona-Arias, 2015; Hoffman \& Dukes, 2008; Kaltsas \& Tsiveriotis, 2013; Soriano-Maldonado et al., 2015).

The impact of stress, anxiety and depression on FM is defined. In the current research it was found that the higher severity of depression and anxiety, the patients had a higher degree of severity in the FM, agrees with other studies where it is concluded that the severity of depression and anxiety are correlated with the severity of fibromyalgia (Aguglia et al., 2011; Alok et al., 2010; Aparicio et al., 2013; Martinez et al., 2013; Moreno et al., 2010; Soriano-Maldonado et al., 2015).

In relation to the subjective perception of quality of life and the severity of the FM, it was found that the higher the scores in the FIQR, the lower the weighted scores for quality of life in the participants. The correlation of these two variables always tends to be evaluated indirectly in the studies.

\section{Conclusions}

The data obtained in this study corroborate those found in the literature. We found a directly proportional relationship between the severity of depression and anxiety and the severity of FM. A higher score in the FIQR, lower weighted scores for quality of life in the participants, in addition to greater severity in the scales GAD-7 and PHQ-9, lower quality of life.

Within the domains stipulated in SF-36, the emotional role and mental health were among those that presented the highest results. It is recommended to conduct a new study in the same population to determine the characteristics or personality traits of the participants.

It is also recommended to conduct studies with the SF-36 at a local level in a healthy population and compare the data obtained in patients with FM, and thus measure the commitment of this condition.

This is the first study in the Colombian Caribbean Region that performs an analysis of the different variables mentioned above. The information obtained can serve as a basis for future research to determine psychiatric causal factors of fibromyalgia.

\section{Competing Interests Statement}

The authors declare that there are no competing or potential conflicts of interest.

\section{References}

Aguglia, A., Salvi, V., Maina, G., Rossetto, I., \& Aguglia, E. (2011). Fibromyalgia syndrome and depressive symptoms: comorbidity and clinical correlates. Journal of Affective Disorders, 128(3), 262-266. https://doi.org/10.1016/j.jad.2010.07.004

Alok, R., Das, S. K., Agarwal, G. G., Salwahan, L., \& Srivastava, R. (2010). Relationship of severity of depression, anxiety and stress with severity of fibromyalgia. Clinical and Experimental Rheumatology, 29(6 Suppl 69), S70-2.

Aparicio, V. A., Ortega, F. B., Carbonell-Baeza, A., Cuevas, A. M., Delgado-Fernández, M., \& Jonatan, R. (2013). Anxiety, depression and fibromyalgia pain and severity. Psicología Conductual, 21(2), 381.

Bannwarth, B., Blotman, F., Roué-Le Lay, K., Caubère, J.-P., André, E., \& Taïeb, C. (2009). Fibromyalgia syndrome in the general population of France: A prevalence study. Joint Bone Spine, 76(2), 184-187. https://doi.org/10.1016/j.jbspin.2008.06.002

Björkegren, K., Wallander, M.-A., Johansson, S., \& Svärdsudd, K. (2009). General symptom reporting in female fibromyalgia patients and referents: a population-based case-referent study. BMC Public Health, 9, 402. https://doi.org/10.1186/1471-2458-9-402

Buskila, D., Atzeni, F., \& Sarzi-Puttini, P. (2008). Etiology of fibromyalgia: the possible role of infection and vaccination. Autoimmunity Reviews, 8(1), 41-43. https://doi.org/10.1016/j.autrev.2008.07.023

Chavez Hidalgo, D. (2013). Actualización en fibromialgia. Medicina Legal de Costa Rica, 30(1), 83-8.

Chinn, S., Caldwell, W., \& Gritsenko, K. (2016). Fibromyalgia pathogenesis and treatment options update. Current Pain and Headache Reports, 20(4), 25. https://doi.org/10.1007/s11916-016-0556-x

Clauw, D. J. (2014). Fibromyalgia: a clinical review. Jama, 311(15), 1547-1555. https://doi.org/10.1001/jama.2014.3266

Cunningham, M. M., \& Jillings, C. (2006). Individuals' Descriptions of Living With Fibromyalgia. Clinical Nursing Research, 15(4), 258-273. https://doi.org/10.1177/1054773806291853 
de Vida, C., \& Fibromialgia, C. P. (2010). Fibromyalgia and psychiatric comorbidity: their effect on the quality of life patients. Actas Esp Psiquiatr, 38(5), 295-300.

Fernández Ávila, D. G. (2016). Fibromialgia, una llamada al manejo multidisciplinario. Revista Colombiana de Reumatología, 23(1), 1-2. https://doi.org/10.1016/j.rcreu.2016.01.002

Fietta, P., \& Manganelli, P. (2007). Fibromyalgia and psychiatric disorders. Acta Bio Medica Atenei Parmensis, 78(2), 88-95.

Hernández-Petro, A. M., \& Cardona-Arias, J. A. (2015). Efecto de la fibromialgia sobre el estado de salud y la calidad de vida relacionada con la salud, 2004-2014. Revista Colombiana de Reumatología, 22(2), 110-118. https://doi.org/10.1016/j.rcreu.2015.03.005

Hoffman, D. L., \& Dukes, E. M. (2008). The health status burden of people with fibromyalgia: a review of studies that assessed health status with the SF-36 or the SF-12. International Journal of Clinical Practice, 62(1), 115-126. https://doi.org/10.1111/j.1742-1241.2007.01638.x

Jiao, J., Vincent, A., Cha, S. S., Luedtke, C. A., \& Oh, T. H. (2014). Relation of age with symptom severity and quality of life in patients with fibromyalgia. Mayo Clinic Proceedings, 89(2), 199-206. https://doi.org/10.1016/j.mayocp.2013.09.021

Kaltsas, G., \& Tsiveriotis, K. (2013). Fibromyalgia.

Kool, M. B., van Middendorp, H., Boeije, H. R., \& Geenen, R. (2009). Understanding the lack of understanding: invalidation from the perspective of the patient with fibromyalgia. Arthritis Care \& Research, 61(12), 1650-1656. https://doi.org/10.1002/art.24922

Lawrence, R. C., Felson, D. T., Helmick, C. G., Arnold, L. M., Choi, H., Deyo, R. A., ... Wolfe, F. (2008). Estimates of the prevalence of arthritis and other rheumatic conditions in the United States. Part II. Arthritis and Rheumatism, 58(1), 26-35. https://doi.org/10.1002/art.23176

Martinez, J. E., de Melo Casagrande, P., Ferreira, P. P. R., \& Rossatto, B. L. G. (2013). Correlação entre variáveis demográficas e clínicas, e a gravidade da fibromialgia. Revista Brasileira de Reumatologia, 53(6), 460-463. https://doi.org/10.1016/j.rbr.2013.04.002

McNally, J. D., Matheson, D. A., \& Bakowsky, V. S. (2006). The epidemiology of self-reported fibromyalagia in Canada. Chronic Diseases and Injuries in Canada, 27(1), 9.

Ministerio de Salud y Protección Social de Colombia. Resolución 8430 de 1993 (1993). Colombia.

Moreno, V., Namuche, F., Noriega, A. E., Vidal, M., Rueda, C., Pizarro, J., \& Vidal, L. (2010). Sintomatología depresiva en pacientes con fibromialgia. In Anales de la Facultad de Medicina (Vol. 71, pp. 23-27). UNMSM. Facultad de Medicina. https://doi.org/10.15381/anales.v71i1.68

Moukaddem, A., Chaaya, M., Slim, Z. F. N., Jaffa, M., Sibai, A. M., \& Uthman, I. (2015). Fibromyalgia: epidemiology and risk factors, a population-based case-control study in Lebanon. International Journal of Rheumatic Diseases.

Moukaddem, A., Chaaya, M., Slim, Z. F. N., Jaffa, M., Sibai, A. M., \& Uthman, I. (2017). Fibromyalgia: epidemiology and risk factors, a population-based case-control study in Lebanon. International Journal of Rheumatic Diseases, 20(2), 169-176. https://doi.org/10.1111/1756-185X.12701

Queiroz, L. P. (2013). Worldwide epidemiology of fibromyalgia. Current Pain and Headache Reports, 17(8), 356. https://doi.org/10.1007/s11916-013-0356-5

Soriano-Maldonado, A., Amris, K., Ortega, F. B., Segura-Jiménez, V., Estévez-López, F., Álvarez-Gallardo, I. C., ... Ruiz, J. R. (2015). Association of different levels of depressive symptoms with symptomatology, overall disease severity, and quality of life in women with fibromyalgia. Quality of Life Research, 24(12), 2951-2957. https://doi.org/10.1007/s11136-015-1045-0

Talotta, R., Bazzichi, L., Di Franco, M., Casale, R., Batticciotto, A., Gerardi, M., \& Sarzi-Puttini, P. (2017). One year in review 2017: fibromyalgia. Clin Exp Rheumatol, 35(105), S6-S12.

Weir, P. T., Harlan, G. A., Nkoy, F. L., Jones, S. S., Hegmann, K. T., Gren, L. H., \& Lyon, J. L. (2006). The incidence of fibromyalgia and its associated comorbidities: a population-based retrospective cohort study based on International Classification of Diseases, 9th Revision codes. JCR: Journal of Clinical Rheumatology, 12(3), 124-128. https://doi.org/10.1097/01.rhu.0000221817.46231.18 


\section{Copyrights}

Copyright for this article is retained by the author(s), with first publication rights granted to the journal.

This is an open-access article distributed under the terms and conditions of the Creative Commons Attribution license (http://creativecommons.org/licenses/by/4.0/). 